\title{
Quality control of the blood pressure phenotype in the European Project on Genes in Hypertension Tatiana Kuznetsova ${ }^{a, g}$, Jan A. Staessen ${ }^{a}$, Kalina Kawecka- Jaszcz $^{\mathrm{b}}$, Speranta Babeanuc ${ }^{\mathrm{c}}$, Edoardo Casiglia ${ }^{\mathrm{d}}$, Jan Filipovsky ${ }^{e}$, Choudomir Nachev ${ }^{f}$, Yuri Nikiting, Jan Peleskã ${ }^{h}$ and Eoin O'Brien', on behalf of the EPOGH investigators
}

Objectives In the European Project on Genes in Hypertension (EPOGH) standardized epidemiological methods were used to determine complex phenotypes consisting of blood pressure (BP) in combination with other traits. In this report, we present the quality control of one of the BP phenotypes.

Methods In seven European countries eight different research groups recruited random samples of nuclear families. Trained observers measured the BP five times consecutively with the participants in the seated position at each of two separate home visits, 1 to 3 weeks apart, according to the guidelines of the British Hypertension Society. Quality assurance and quality control of this BP phenotype were implemented according to detailed instructions defined in the protocol of the EPOGH study.

Results On 31 August 2001, BP measurements of 2476 subjects were available for analysis. Fewer BP readings than the five planned per visit occurred in one of the eight centres, but only in $0.4 \%$ of the home visits. Across centres the relative frequency of identical consecutive readings for systolic or diastolic blood pressure varied from 0 to $6 \%$. The occurrence of odd readings ranged from 0 to $0.1 \%$. Of the 49488 systolic and diastolic BP readings, $24.0 \%$ ended on a zero (expected 20\%). In most EPOGH centres there was a progressive decline in the BP from the first to the second home visit. Overall, these decreases averaged $2.36 \mathrm{mmHg}$ [95\% confidence interval (Cl): 1.98-2.74, $P<0.001]$ for systolic $\mathrm{BP}$ and $1.74 \mathrm{mmHg}(95 \% \mathrm{Cl}$ : 1.46-2.02, $P<0.001$ ) for diastolic BP.

Conclusions Quality assurance and control should be planned at the design stage of a project involving BP measurement and implemented from its very beginnings until the end. The procedures of quality assurance set up in the EPOGH study for the BP measurements resulted in a well-defined BP phenotype, which was consistent across centres. Blood Press Monit 7: 215224 (c) 2002 Lippincott Williams \& Wilkins.

Blood Pressure Monitoring 2002, 7:215-224
Keywords: blood pressure phenotype, population, data quality, trends

"Study Coordinating Centre, Hypertension and Cardiovascular Rehabilitation Unit, Department of Molecular and Cardiovascular Research, University of Leuven, Leuven, Belgium; b/ Cardiac Department and Department of Gerontology, Jagiellonian University, Cracow, Poland; 'San Luca Hospital, Bucharest, Romania; 'Department of Clinical and Experimental Medicine, University of Padova, Italy; "Charles University, Pilsen, Czech Republic; Alexandrov University Hospital, Sofia, Bulgaria; Institute of Internal Medicine, Novosibirsk, Russian Federation; "General Faculty Hospital, Prague, Czech Republic and The Blood Pressure Unit, Beaumont Hospital, Dublin, Ireland.

Sponsorship: The European Project on Genes in Hypertension was supported by the European Union (contract numbers IC15-CT98-0329 EPOGH and QLG1-CT-2000-01137-EURNETGEN). The study was also supported by research grants G.0174.97 and G.0291.98 from the Fonds voor Wetenschappelijk Onderzoek Vlaanderen (Brussels, Belgium), by a special research grant (Onderzoekstoelage OT/99/28) from the Katholieke Universiteit Leuven (Leuven, Belgium), by a research grant (OK 375) from the Czech Ministry of Education, and by the Internationale

Wetenschappelijke en Technologische Samenwerking Polen-Vlaanderen (grant 00/18). The study was carried out in consultation with the Working Groups on Blood Pressure Measurement and Large Arteries of the European Society of Hypertension.

Correspondence and requests for reprints to Tatiana Kuznetsova, MD Studiecoóndinatiecentrum, Laboratorium Hypertensie, Campus Gasthuisberg, Herestraat 49, B-3000 Leuven, Belgium. Tel: +32 1634 5767; fax: +32 1634 7106/5763; e-mail: tatiana.kouznetsova@student.kuleuven.ac.be

Received 17 December 2001 Revised 04 March 2002 Accepted 06 March 2002

\section{Introduction}

Accurate measurement of the blood pressure phenotype is of paramount importance in studies on the genetic determination of hypertension [1]. In most studies in humans, the blood pressure phenotype is the mean of three to five readings obtained in a single occasion. A number of automated electronic devices have become available for blond pressure measurement under static or ambulatory conditions [2-4]. However, until now auscultatory blood pressure measurement using the Riva-Rocci/Korotkoff technique remains the standard in clinical and epidemiological research.

The European Project on Genes in Hypertension (EPOGH) involves eight centres in seven European countries. Its main objective is to identify genetic polymorphisms that are significantly associated with blood pressure as a continuous or dichotomous trait. In addition to ambulatory blood pressure monitoring and measurement of the clinic blood pressure, the blood pressure phenotype 
in the EPOGH study also consists of five consecutive blood pressure readings obtained with the subjects seated at each of two separate home visits. Intra- and inter-observer variability in blood pressure measurements may already be large in single-centre studies and may even further increase in large-scale epidemiological projects, involving multiple centres. In this article we present the initial progress of the EPOGH study together with the results of the quality control programme of the blood pressure phenotype measured at the participants' homes.

\section{Methods}

\section{Fieldwork}

Random samples of nuclear families were recruited in Hechtel-Eksel [Belgium (B)], Sofia [Bulgaria (BU)], Pilsen and Prague [Czech Republic (CZ)], Mirano [Padova, Italy (I)], Cracow [Poland (PL)], Bucharest [Romania (RO)], and Novosibirsk [Russian Federation (RF)]. To increase the number of hypertensive patients, four groups (those of Padova, Cracow, Bucharest, and Novosibirsk) also recruited approximately $30 \%$ of the required number of nuclear families via specialized clinics for hypertensive patients.

Nuclear families had to include at least one parent and two siblings. The minimum age for participation was 10 years. Family members had to live within a distance of no more than approximately $10 \mathrm{~km}$ to make repeated home visits feasible.

Trained observers measured blood pressure with a standard mercury sphygmomanometer five times consecutively during each of two home visits. The guidelines of the British Society of Hypertension [5] were applied. Standard cuffs had a $12 \times 24 \mathrm{~cm}$ inflatable bladder, but, if upper arm circumference exceeded $.31 \mathrm{~cm}$, larger cuffs with $15 \times 35 \mathrm{~cm}$ bladder were used. After at least $10 \mathrm{~min}$ rest, five consecutive blood pressure readings were obtained in the sitting position with an interval of 30 to $60 \mathrm{~s}$ between readings. The cuff was deflated at approximately $2 \mathrm{mmHg}$ per second, and systolic and phase $V$ diastolic blood pressure were recorded to the nearest $2 \mathrm{mmHg}$. Each subject's conventional blood pressure was the mean of the 10 readings obtained at home.

\section{Quality assurance procedures}

Quality assurance refers to the procedures set up at all centres to ensure high quality blood pressure measurements throughout the project. At the start of the EPOGH study (November 1998), we organized a 1-week workshop at the Coordinating Office in Leuven, Belgium. Subsequently, during the course of the study, investigators of four centres requested further training and visited the Coordinating Office, respectively, in June 1999, June 2000, October 2000, and February 2001. On each occasion, the investigators took a refresher course on the procedures of blond pressure measurement.

At each field centre, quality assurance sessions were organized at three to six monthly intervals to reinforce the theoretical concepts and to rehearse the practical procedures of sphygmomanometric blood pressure measurement. At each session the observers had to pass a test requiring them to read blood pressures from videotape featuring a falling mercury column with simultaneous Korotkoff sounds (Measuring Blood Pressure; British Medical Association, London, 1990). For each session a specific standard was computed which reflected the acoustic conditions under which the test had taken place, and which was computed by averaging the film readings of experienced senior clinical researchers. All readings from each observer had to be within $5 \mathrm{mmHg}$ of the standard. If an observer failed to pass the test, she/he did not participate in blood pressure measurement until re-tested successfully at a later session. The intra-observer reproducibility was studied by comparing 10 pairs of identical video simulations of blood pressure measurements and was calculated as twice the standard deviation of the differences between duplicate readings. Moreover, the reproducibility coefficient was expressed as a percentage of the mean of the identical readings. Digit preference was not evaluated at the training sessions, but computed from the blood pressure measurements in study participants.

All observers involved in the study completed a questionnaire providing information on their gender, age, and qualification (paramedic, nurse, or medical doctor). In addition, in the same questionnaire, the observers provided information on the technical characteristics of the sphygmomanometers used for blood pressure measurement at subjects' homes (aneroid versus mercury; cuff size).

\section{Quality control}

The present analysis includes the blond pressure readings obtained at the participants' homes and made available to the Coordinating Office before 31 August 2001. From published guidelines $[5,6]$ and six previous studies [7-12] we selected six criteria applicable to the design and the multicentre character of the EPOGH study:

1. In each participant, the blood pressure measurements were considered as complete if all five systolic and diastolic blood pressure readings at each of the two separate home visits were available in the database.

2. Five consecutive blood pressure readings obtained in a subject were considered as identical, if there was no single difference between any of the systolic or diastolic blood pressure values among the five readings. The frequency of consecurive five identical readings was determined. 
3. The proporcion of odd blood pressure readings with as terminal digit $1,3,5,7$, or 9 was determined for systolic and diastolic measurements separately.

4. Digit preference, i.e., the distribution of the last digits of all single systolic and diastolic blood pressure readings was monitored at three-monthly intervals throughour the EPOGH project.

5. To assess the consistency between centres, we evaluated the blood pressure changes from the first to the second home visit and across the ten readings obtained at the two home visits.

6. To investigate the pattern of variation between observers, the mean for each individual observer's blood pressure readings was compured and compared with the overall within-centre mean.

\section{Statistical analysis}

We used the SAS software package, version 6.12. (SAS Institute, Cary, North Carolina, USA) for database management and statistical analysis. Comparison of means and proportions were performed with the standard normal ztest and the $\chi^{2}$-statistic, respectively. To assess intraobserver variability, Bland and Altman's technique [13] was applied. We used analysis of covariance to compare blood pressure measurements between observers with adjustment for sex, age, body mass index, antihypertensive treatment, smoking, alcohol intake, and the use of oral contraceptives. To compare trends in the consecutive blond pressure measurements between centres we used repeated measures analysis of variance and we determined the significance of the interaction terms between centre and the order of the blood pressure readings.

\section{Results}

\section{Characteristics of the study population}

The 2476 participants included 1173 men (47.4\%) and 605 hypertensive patients (24.4\%) of whom 328 were on antihypertensive drug treatment (Table 1). The subjects ranged in age from 10 to 84 years. Among the men, $32.5 \%$ $(n=374)$ were current smokers, and $57.8 \%(n=661)$ reported intake of alcohol. In women, these proportions were $21.4 \%(n=273)$ and $36.1 \%(n=460)$, respectively. Among women, $20.0 \%(n=261)$ used oral contraceptives.

\section{Characteristics of the observers}

The number of observers employed per centre ranged from one to six (Table 2). The observers' age ranged from 25 to 62 years. Most observers (84\%) were female and/or medical doctors (77\%). Two centres employed only nurses for measuring blood pressure during the study (Table 2). The number of blond pressure readings per observer ranged from 60 to 4560 . All centres used standard mercury sphygmomanometers and adjusted cuff size according to arm circumference.

\section{Video test}

Table 3 summarizes the results of all training sessions by centre and gives for each centre the distribution of the differences between the observers' film readings and the standard (20 differences per observer during one training session) and the intra-observer reproducibility. Overall, $\mathbf{8 8 \%}$ of the observers' systolic pressure readings were within $\pm 5 \mathrm{mmHg}$ of the standard. For diastolic pressure this proportion was $\mathbf{8 7 . 4 \%}$. The repeatability coefficient across seven centres and 29 observers was $5.4 \%$ for systolic pressure and $6.4 \%$ for diastolic pressure.

\section{Quality control according to six predefined criteria}

Fewer blond pressure readings than the five projected per visit occurred in one of the eight centres, but only in $0.4 \%$. of the home visits (Table 4). The frequency of identical consecutive readings for systolic or diastolic blood pressure varied across the centres from 0 to $6 \%$. The occurrence of odd readings which represented a deviation from the study protocol, ranged from 0 to $0.1 \%$. Of 49488 systolic and diastolic blood pressure readings, $24.0 \%$ ended on a zero (Fig. 1). The difference with the expected frequency of $20 \%$ was statistically significant $\left(\chi^{2}=390.5 ; P<0.001\right)$.

Table 1 Characteristics of the participants

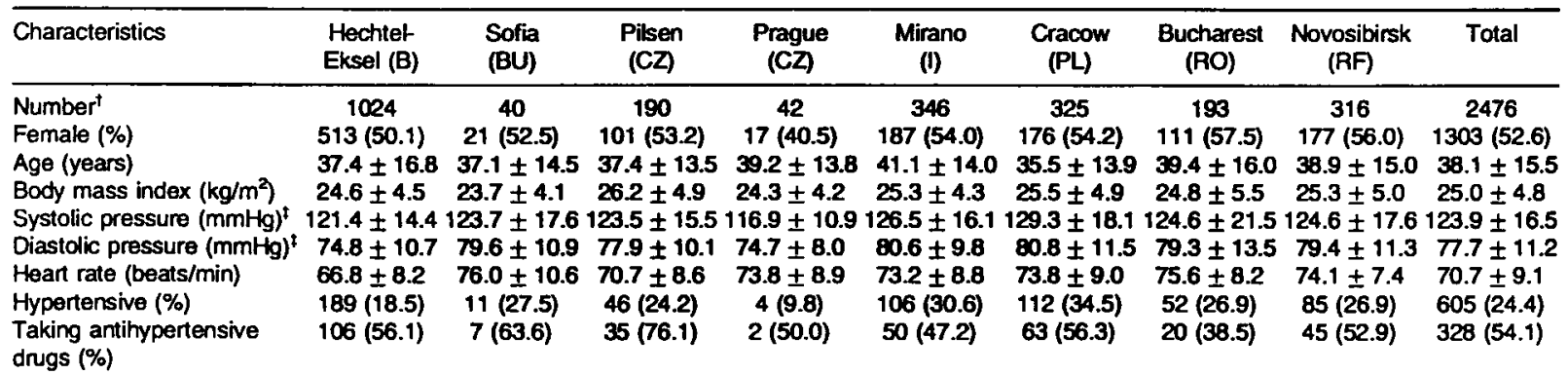

Values are arithmetic means (SD), or number of subjects (\%). 'Number of subjects with data available at the Coordinating Office. ${ }^{\mathrm{T}}$ Average of 10 readings at the first and second home visit. 
218 Blood Pressure Monitoring 2002, Vol 7 No 4

Tabla 2 Characteristics of observers

\begin{tabular}{|c|c|c|c|c|c|c|}
\hline \multirow[t]{2}{*}{ Centre } & \multicolumn{2}{|c|}{ Age group (years) } & \multicolumn{2}{|c|}{ Gender } & \multicolumn{2}{|c|}{ Qualification } \\
\hline & $25-35$ & $>35$ & Male & Female & Nurse & Doctor \\
\hline Hechtel-Eksel (B) $n=4$ & $2(50 \%)$ & $2(50 \%)$ & - & $4(100 \%)$ & $4(100 \%)$ & - \\
\hline Sofia (BU) $n=2$ & $2(100 \%)$ & - & $1(50 \%)$ & $1(50 \%)$ & - & $2(100 \%)$ \\
\hline Pilsen $(C Z) n=3$ & $2(67 \%)$ & $1(33 \%)$ & - & $3(100 \%)$ & $1(33 \%)$ & $2(67 \%)$ \\
\hline Prague $(\mathrm{CZ}) n=1$ & - & 1 & - & 1 & 1 & - \\
\hline Mirano (I) $n=6$ & $4(67 \%)$ & $2(33 \%)$ & $2(33 \%)$ & $4(67 \%)$ & - & $6(100 \%)$ \\
\hline Cracow $(P L) n=6$ & $4(67 \%)$ & $2(33 \%)$ & $1(17 \%)$ & $5(83 \%)$ & $1(17 \%)$ & $5(83 \%)$ \\
\hline Bucharest (RO) $n=6$ & $2(33 \%)$ & $4(67 \%)$ & $1(17 \%)$ & $5(83 \%)$ & - & $6(100 \%)$ \\
\hline Novosibirsk (RF) $n=3$ & $2(67 \%)$ & $1(33 \%)$ & - & $3(100 \%)$ & - & $3(100 \%)$ \\
\hline Total $n=31$ & $18(58 \%)$ & $13(42 \%)$ & $5(16 \%)$ & $26(84 \%)$ & $7(23 \%)$ & $24(77 \%)$ \\
\hline
\end{tabular}

Table 3 Results of training sessions for observers

\begin{tabular}{|c|c|c|c|c|c|c|c|c|c|c|c|c|c|c|c|c|}
\hline \multirow{2}{*}{$\begin{array}{l}\text { Centre } \\
\text { Number of } \\
\text { sessions }\end{array}$} & \multicolumn{2}{|c|}{$\begin{array}{c}\text { Hechtel-Eksel } \\
\text { (B) } \\
5\end{array}$} & \multicolumn{2}{|c|}{$\begin{array}{c}\text { Sofia } \\
(B U)^{\dagger} \\
1\end{array}$} & \multicolumn{2}{|c|}{$\begin{array}{c}\text { Pilsen } \\
\text { (CZ) } \\
1\end{array}$} & \multicolumn{2}{|c|}{$\begin{array}{c}\text { Prague } \\
\text { (CZ) } \\
1\end{array}$} & \multicolumn{2}{|c|}{$\begin{array}{c}\text { Mirano } \\
\text { (1) } \\
7\end{array}$} & \multicolumn{2}{|c|}{$\begin{array}{c}\text { Cracow } \\
(P L) \\
5\end{array}$} & \multicolumn{2}{|c|}{$\begin{array}{c}\text { Bucharest } \\
\text { (RO) } \\
2\end{array}$} & \multicolumn{2}{|c|}{$\begin{array}{c}\text { Novosibirsk } \\
\text { (RF) } \\
5\end{array}$} \\
\hline & $\begin{array}{l}\text { SBP } \\
(\%)\end{array}$ & $\begin{array}{c}\text { DBP } \\
(\%)\end{array}$ & $\begin{array}{l}\text { SBP } \\
(\%)\end{array}$ & $\begin{array}{c}\text { DBP } \\
(\%)\end{array}$ & $\begin{array}{l}\text { SBP } \\
(\%)\end{array}$ & $\begin{array}{c}\text { DBP } \\
(\%)\end{array}$ & $\begin{array}{c}\text { SBP } \\
(\%)\end{array}$ & $\begin{array}{c}\text { DBP } \\
(\%)\end{array}$ & $\begin{array}{c}\text { SBP } \\
(\%)\end{array}$ & $\begin{array}{l}\text { DBP } \\
(\%)\end{array}$ & $\begin{array}{l}\text { SBP } \\
(\%)\end{array}$ & $\begin{array}{c}\text { DBP } \\
(\%)\end{array}$ & $\begin{array}{l}\text { SBP } \\
(\%)\end{array}$ & $\begin{array}{c}\text { DBP } \\
(\%)\end{array}$ & $\begin{array}{l}\text { SBP } \\
(\%)\end{array}$ & $\begin{array}{l}\text { DBP } \\
(\%)\end{array}$ \\
\hline \multicolumn{17}{|c|}{ Deviation of observers' readings vs. reference } \\
\hline$>10 \mathrm{mmHg}$ & 1.5 & 0.5 & 0 & 0 & 0 & 0 & $\mathbf{0}$ & 0 & 3.3 & $\mathbf{3 . 3}$ & 1.3 & 3.0 & 1.9 & 4.4 & 0 & 0 \\
\hline $8-10 \mathrm{mmHg}$ & 1.8 & 2.8 & 5.0 & 5.0 & $\mathbf{0}$ & 0 & 0 & 0 & 0 & 1.3 & 2.5 & 0 & 3.8 & 3.7 & 0 & 0 \\
\hline $5-7 \mathrm{mmHg}$ & 5.5 & 3.5 & 5.0 & 0 & 0 & 0 & 0 & 0 & 1.5 & 0.8 & 4.3 & 1.8 & 5.6 & 7.5 & 0 & 0 \\
\hline $2-4 \mathrm{mmHg}$ & 31.5 & 30.8 & 5.0 & 20.0 & 16.7 & 30.0 & 10.0 & 25.0 & 4.8 & 11.9 & 12.2 & 15.0 & 25.0 & 21.3 & 25.0 & 16.0 \\
\hline-1 to $1 \mathrm{mmHg}$ & 39.3 & 38.3 & 80.0 & 65.0 & 53.3 & 45.0 & 35.0 & 45.0 & 62.7 & 45.8 & 51.2 & 50.7 & 47.5 & 35.0 & 65.0 & 68.0 \\
\hline-2 to $-4 \mathrm{mmHg}$ & 14.8 & 21.3 & 5.0 & 10.0 & 30.0 & 25.0 & 50.0 & 30.0 & 20.8 & 27.1 & 23.7 & 23.2 & 11.8 & 13.1 & 10.0 & 14.0 \\
\hline-5 to $-7 \mathrm{mmHg}$ & 0.8 & 0.8 & 0 & 0 & 0 & 0 & 5.0 & 0 & 5.0 & 8.1 & 1.8 & 4.0 & 1.9 & 4.4 & 0 & 2.0 \\
\hline-8 to $-10 \mathrm{mmHg}$ & 2.3 & 0.8 & 0 & 0 & 0 & 0 & 0 & 0 & 1.3 & 1.0 & 1.5 & 1.2 & 1.3 & 3.1 & 0 & 0 \\
\hline$<-10 \mathrm{mmHg}$ & 2.8 & 1.5 & 0 & 0 & 0 & 0 & 0 & 0 & 0.6 & 0.6 & 1.5 & 1.2 & 1.2 & 7.5 & 0 & 0 \\
\hline Reproducibility & $\begin{array}{c}5.2 \\
(3.3)\end{array}$ & $\begin{array}{c}6.8 \\
(6.3)\end{array}$ & $\begin{array}{c}4.0 \\
(2.4)\end{array}$ & $\begin{array}{c}9.5 \\
(8.7)\end{array}$ & $\begin{array}{c}2.7 \\
(1.6)\end{array}$ & $\begin{array}{c}3.6 \\
(3.4)\end{array}$ & $\begin{array}{c}2.8 \\
(1.9)\end{array}$ & $\begin{array}{c}2.8 \\
(2.6)\end{array}$ & $\begin{array}{c}8.8 \\
(5.3)\end{array}$ & $\begin{array}{r}6.6 \\
(6.0)\end{array}$ & $\begin{array}{l}13.7 \\
(8.1)\end{array}$ & $\begin{array}{c}5.7 \\
(5.3)\end{array}$ & $\begin{array}{c}9.4 \\
(5.3)\end{array}$ & $\begin{array}{c}10.9 \\
(10.4)\end{array}$ & $\begin{array}{c}2.2 \\
(1.4)\end{array}$ & $\begin{array}{c}3.0 \\
(2.9)\end{array}$ \\
\hline
\end{tabular}

Observers read 20 blood pressures per session from a video movie showing a falling mercury column with Korotkoft sounds. "One observer's result not yet available at the Coordinating Office at the time of writing of this article. ${ }^{2} 2 \mathrm{SO}$ of the changes between identical blood pressures from a video movie. See Methods for further explanations. SBP, systolic biood pressure; DBP, diastolic blood pressure.

Table 4 Qualitative indicators for control of blood pressure measurement

\begin{tabular}{|c|c|c|c|c|c|c|c|c|}
\hline & $\begin{array}{c}\text { Hechtel-Eksel } \\
\text { (B) }\end{array}$ & $\begin{array}{l}\text { Sofia } \\
\text { (BU) }\end{array}$ & $\begin{array}{l}\text { Pilsen } \\
\text { (CZ) }\end{array}$ & $\begin{array}{l}\text { Prague } \\
\text { (CZ) }\end{array}$ & $\begin{array}{l}\text { Mirano } \\
\text { (I) }\end{array}$ & $\begin{array}{l}\text { Cracow } \\
\text { (PL) }\end{array}$ & $\begin{array}{c}\text { Bucharest } \\
\text { (RO) }\end{array}$ & $\begin{array}{l}\text { Novosibirsk } \\
\text { (RF) }\end{array}$ \\
\hline & $n(\%)$ & $n(\%)$ & $n(\%)$ & $n(\%)$ & $n(\%)$ & $n(\%)$ & $n(\%)$ & $n(\%)$ \\
\hline Number of home visits & 2103 & 80 & 380 & 84 & 692 & 650 & 398 & 632 \\
\hline Incomplete BP measurements ${ }^{\dagger}$ & $8(0.4 \%)$ & 0 & 0 & $\mathbf{0}$ & 0 & 0 & 0 & 0 \\
\hline Number of five consecutive BP readings ${ }^{t}$ & 4206 & 160 & 760 & 168 & 1384 & 1300 & 796 & 1264 \\
\hline Identical readings & $66(1.6 \%)$ & $1(0.6 \%)$ & 0 & $10(6.0 \%)$ & $41(3.0 \%)$ & $1(0.1 \%)$ & $1(0.7 \%)$ & 0 \\
\hline Total number of BP readings ${ }^{\ddagger}$ & 21018 & 800 & 3800 & 840 & 6920 & 6500 & 3980 & 6320 \\
\hline Odd readings & $7(0.03 \%)$ & $1(0.1 \%)$ & 0 & $1(0.1 \%)$ & $6(0.08 \%)$ & $6(0.09 \%)$ & 0 & 0 \\
\hline
\end{tabular}

'Less than five systolic or five diastolic measurements per home visit. 'Systolic and diastolic readings were counted as separate measurements.

Among individual observers the proportion of blood pressure readings with a terminal zero ranged from 15.5 to $47.6 \%$ (Table 5). Five observers in three centres were found to record blood pressure values with a terminal zero in excess of $30 \%(47.6,32.9,31.8,31.5$ and $31.4 \%)$.

In most EPOGH centres there was a significant and progressive decline in the conventional blond pressure from the first to the second home visit (Fig. 2). Across all centres, blood pressure decreased by $2.36 \mathrm{mmHg}(95 \%$ confidence interval (CI): 1.98-2.74, $P<0.001$ ) systolic and by $1.74 \mathrm{mmHg}$ (95\% CI: $1.46-2.02, P<0.001)$ diastolic. However, as illustrated in Figure 3, there were significant trend differences between the EPOGH centres in the blood pressure changes across the ten readings of systolic $(F=5.32, P<0.001)$ and diastolic blood pressure ( $F=3.71, P<0.001)$. Moreover, the decline of blood pressure on repeat measurement depended on the level of pressure (Figs 2 and 3). For instance, in comparison with other EPOGH centres, we observed more prominent 


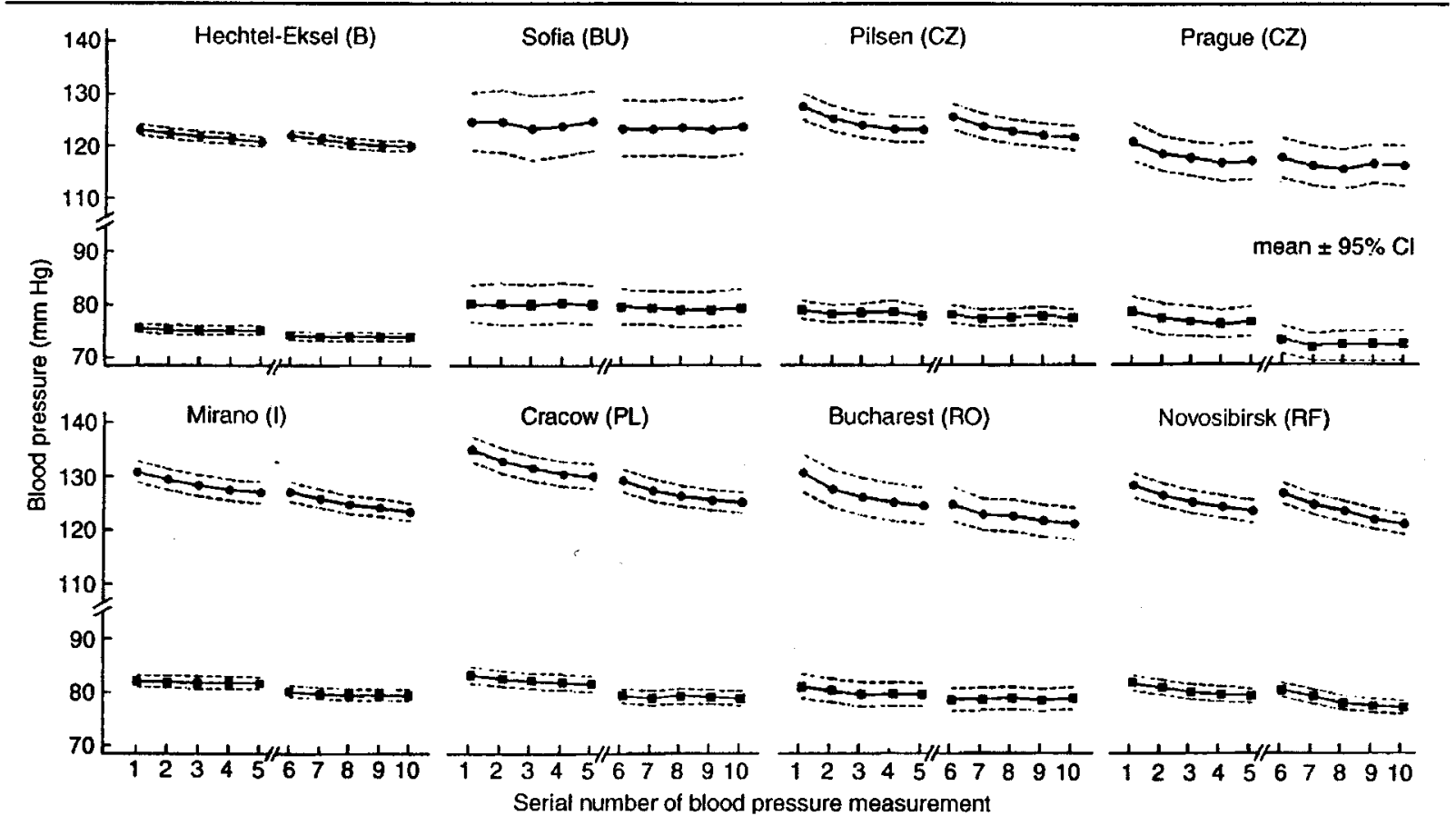

Systolic and diastolic blood pressure values for five consecutive readings at two separate home visits. Values are mean with $95 \%$ confidence intervals.

blood pressure measurements throughout the whole project, in which eight different researches groups and 27 observers participated. Various training programmes have been developed to minimize observer error $[5,6,21]$, most of which use a film or a video showing a falling mercury column with Korotkoff sounds as the main component of training and quality assessment. The film allows quantifying inter- and intra-observer variability. In our study quality assurance was set up via repeated training sessions. The observers always received the results of their tests, so that they remained aware of their performance and were encouraged to improve their measurement technique.

In our quality control programme we used six criteria, because they reflect different problems that may occur during blood pressure measurement. Some of these items are conceived as qualitative rather than quantitative indicators of the accuracy of blood pressure measurement. The proportion of incomplete measurements is a strong indicator of validity problems in terms of population representativeness [7]. The occurrence of odd digits is likely to reflect forgetfulness of the protocol or a desire for extra accuracy by the observer [10]. It might also indicate a loss of accuracy. The frequency of identical blood pressure readings in series of repeated blood pressure readings might influence the overall shape of the blood pressure distribution and the prevalence of diagnostic categories based on blood pressure thresholds $[10,22]$. It is well known from clinical and epidemiological studies $[9,15,22]$ that repeated blood pressure measurements in the same subject are in most instances non-identical. The degree, to which the frequency of identical readings can be considered normal or at least acceptable, is not clearly defined. All eight EPOGH centres appeared to have complied well with these predefined quality criteria (Table 4).

Owing to habitation and regression to the mean, blood pressure usually falls when repeated measurements are obtained during a single visit or at consecutive visits over the course of a study. In all centres we noticed a progressive and significant decline in blood pressure when the readings were repeated by the observer at the subjects' homes. This observation underscores the need for multiple assessments of blood pressure over a time in order to avoid overdiagnosis of hypertension among individuals with high initial blood pressure values $[2,2,3]$.

The maximal between-centre differences in blood pressure were $12.4 \mathrm{mmHg}$ systolic and $6.1 \mathrm{mmHg}$ diastolic (Prague centre versus Cracow centre). The maximal difference in pulse rate was between the Hechtel-Eksel and Sofia centres ( 9.2 beats per minute). These between-centre 
Measurement of systolic BP
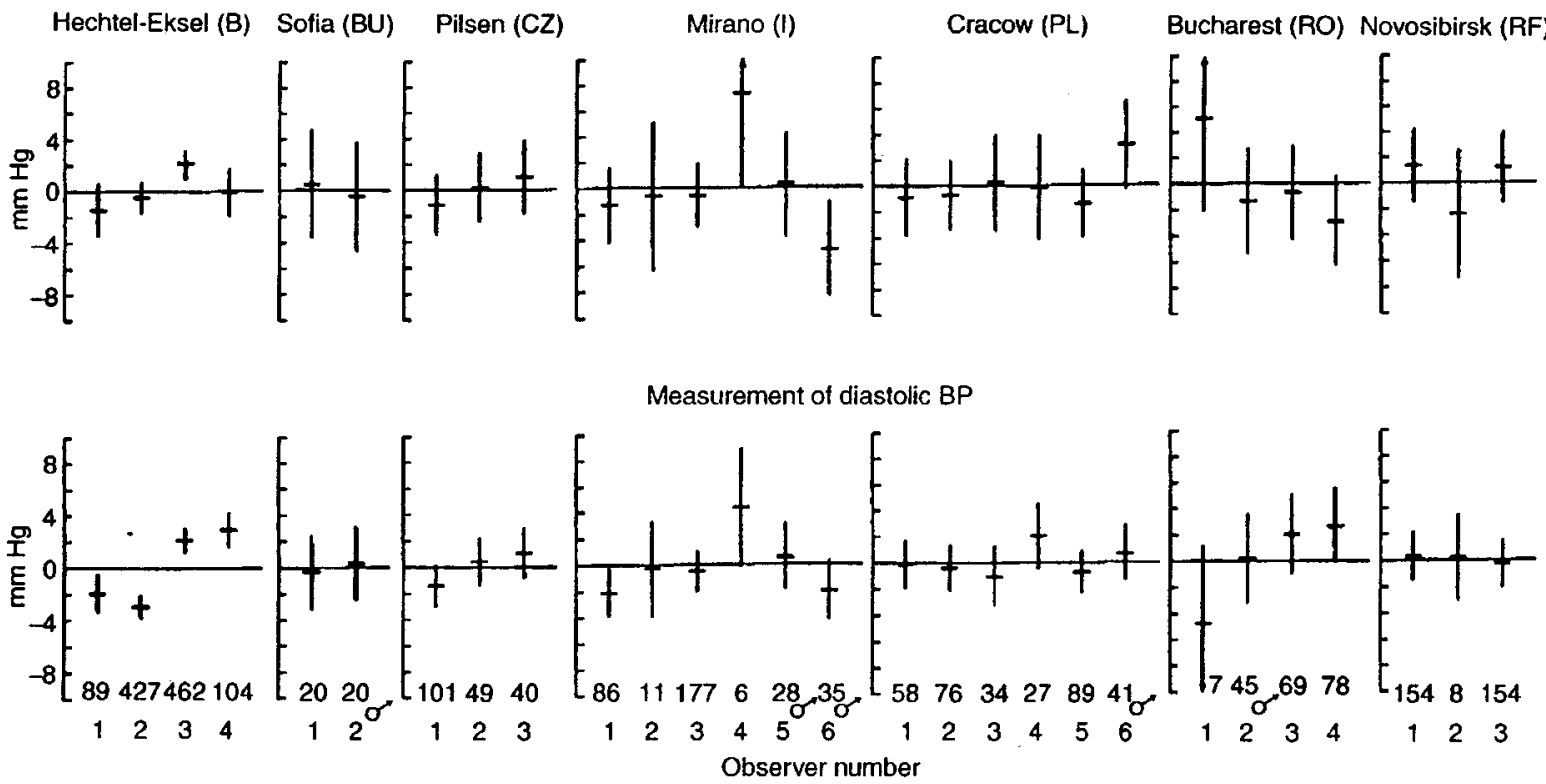

Mean systolic and diastolic differences between each observer's blood pressure (BP) readings and the overall within-centre population means. Values for each observer are point estimates with $95 \%$ confidence interval adjusted for sex, age, body mass index, antihypertensive treatment, smoking, alcohol intake, and the use of oral contraceptives. Along with the observer identification number. gender of the observer ( $s$ if male) and the number of subjects examined by each observer are presented.

differences may be expected on the basis of random variability, small sample size (for instance, in Sofia and Prague), and inclusion of varying proportions of hypertensive subjects.

Another common manifestation of measurement error in epidemiological studies is digit preference for a terminal zero $[9,10,24-26]$. Because this means that the precision of the measurements is $10 \mathrm{mmHg}$ instead of $2 \mathrm{mmHg}$, this may result in considerable bias. Digit preference affects the shape of the blond pressure distribution [24] and reduces the power of statistical tests thereby making it more difficult to assess associations between potential risk factors and blood pressure $[10,26]$. In our report preference for a terminal zero was statistically significant, but of minor importance from a clinical point of view.

The present analysis not only focused on the centres as units of observation, but also included an evaluation of the performance of individual observers. Only a few studies $[6,8,10,21,27]$ have reported data on inter- or intraobserver variability. In our study, we assessed inter-observer variability using the blond pressure readings of expert clinical observers as the standard. Overall, $88 \%$ of the observers' systolic pressure readings were within $\pm 5 \mathrm{mmHg}$ of the standard. For diastolic pressure, this proportion was $\mathbf{8 7 . 4 \%}$. To assess intra-observer variability, we used Bland and Altman's technique. The repeatability coefficient across seven centres and 29 observers was $5.4 \%$ for systolic pressure and $6.4 \%$ for diastolic pressure. Higher repeatability coefficients indicate worse reproducibility. Furthermore, we also evaluated differences between observers, which could not be explained by confounding by gender, age, body mass index, antihypertensive treatment, use of oral contraceptives, smoking, and drinking habits. Differences between observers, over and beyond confounding, might be due to systematic error, prejudice for or against certain blood pressure values, the subjective and emotional interaction between subject and observer, the white-coat effect, and/or random variability $[4,8,18]$.

As opposed, for instance, to biochemical measurements, external quality control cannot be easily mounted for blood pressure readings. However, quality assurance and control should be planned at the design stage of a project involving BP measurement and implemented from its very beginnings until the end. In our opinion, the procedures of quality assurance and control set up for the blood pressure measurement in the frame of the EPOGH study resulted 
in a well-defined blood pressure phenotype, which was consistent across centres.

\section{References}

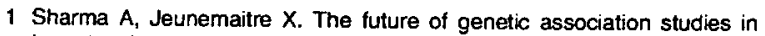
hypertension: improving the signal-to-noise ratio. J Hypertens 2000; 18:811-814.

2 Staessen JA, O'Brien ET, Thijs L, Fagard RH. Modem approaches to blood pressure measurement. Occupa Environ Med 2000; 57:510-520.

3 O'Brien E, Owens P. Classic sphygmomanometry: a fin de siècle reappraisal. In: Bulpitt C (editor): Epidemiology of hypertension. Amsterdam: Elsevier; 2000. pp. 130-151.

4 Bailey $\mathrm{RH}$, Bauer $\mathrm{JH}$. A review of common errors in the indirect measurements of blood pressure. Arch Intem Med 1993; 153:27412748.

5 Petrie JC, O'Brien ET, Littler WA, de Swiet M. Recommendations on blood pressure measurement by a working party of the British Hypertension Society. BM 1989; 293:611-615.

6 O'Brien E, Mee F, Tan KS, Atkins N, O'Malley K. Training and assessment of observers for blood pressure measurement in hypertension research. $J$ Hum Hypertens 1991; 5:7-10.

7 Hense HW, Koivisto A-M, Kuulasmaa K, Zaborskis A, Kupsc W, Tuomilehto J. Assessment of blood pressure measurement quality in the baseline surveys of the WHO MONICA Project. I Hum Hyperten 1995; 9:935-946.

8 Bruce NG, Shaper AG, Walker M, Wannamethee G. Observers bias in blood pressure studies. J Hypertens 1988; 6:375-380.

9 Canner PJ, Borhani NO, Oberman A, Cutler J, Prineas RJ, Langlord $H$, et al. The Hypertension Prevention Trial: assessment of the quality of blood pressure measurements. Am J Epidemiol 1991 134:379-392.

10 Bennett $S$. Blood pressure measurement error: its effect on crosssectional and trend analyses. J Clin Epidemiol 1994; 47:293-301.

11 Dischinger P, Du Chene A. Quality control aspects of blood pressure measurements in the Mutitiple Risk Factor Intervention Trail. Contr Clin Trials 1986; 7:137S-157S.

12 Burke G, Webber L, Shear C, Zinkgraf S, Smoak C, Berenson G. Sources of error in measurement of children's blood pressure in a large epidemiological study: Bogalusa Heart Study. I Chronic Dis 1987; 40:83-89.

13 Bland J, Altman D. Statistical methods for assessing agreement between two methods of clinical measurement. Lancet 1986; i:307310.

14 Arabidze G, Petrov V, Staessen JA. Blood pressure by Korolkolfs auscultatory method: end of an era or bright future? Blood Press Monit auscultatory method:

15 O'Brien $E$, O'Maliey $K$. Clinical blood pressure measurernent. In: Robertson J (editor): Clinical hypertension. Amsterdam: Eisevier; 1992: $14-50$

16 Rose GA, Holland WW, Crowley EA. A sphygmomanometer for epidemiologists. Lancet 1964; 1:296-300.

17 Beevers DG, Beevers $M$. Blood pressure measurements: worsening chaos. I Hum Hypertens 2000; 14:415-416.

18 Engstrom JL. Assessment of the reliability of physical measures. Res Nursing Health 1988; 11:383-389.

19 Staessen JA, Fagard R, Amery A. Life style as a determinant of blood pressure in the general population. Am J Hypertens 1994; 7:685-694.

20 Staessen JA, O'Brien E, Atkins N, Bulpitt CJ, Cox J, Fagard R, et at. The increase in blood pressure with age and body mass index is overestimated by conventiona! sphygmomanometry. Am J Epidemiol 1992; $136: 450-459$.

21 Curb JD, Labarthe DR, Cooper SP, Cutter GR, Hawkins CM. Training and certification of blood pressure observers. Hypertension 1983; 5:610-614.

22 Wietlisbach V, Rickenbach M, Burnand B, Hausser D, Gutzwiller F. Combining repeated blood pressure measurements to obtain prevalence of high blood pressure. Acta Med Scand 1988; 728:165168

23 Stergiou GS, Skeva II. Baibas NM, Kalkana CB, Roussias LG, Mountokalakis TD. Diagnosis of hypertension using home or ambulatory blood pressure monitoring: comparison with the conventional strategy based on repeated clinic blood pressure measurements. I Hypertens 2000; 18:1745-1751.
24 Ataman SL, Cooper R, Rotimi C, McGee D, Osotimehin B, Kadiri S, et al. Standardization of blood pressure measurement in an intemational comparative study. J Clin Epidemiol 1996; 49:869-877.

25 Wen SW, Kramer MS, Hoey J, Hanley JA, Usher RH. Terminal digit preference, random error, and bias in routine clinical measurement of blood pressure. J Clin Epidemiol 1993; 46:1187-1193.

26 Hessel PA. Terminal digit preference in blood pressure measurements: effects on epidemiological associations. Int $J$ Epidemiol 1986; 15:122125.

27 Rose GA. Standardization of observers in blood pressure measurement. Lancet 1965; 1:673-674.

\section{Appendix \\ Coordination and committees \\ Project coordinator}

JA Staessen.

Scientific coordinator

K Kawecka-Jaszcz.

Steering committee

$S$ Babeanu (Romania), E Casiglia (Italy), J Fillipovsky (Czech Republic), K Kawecka-Jaszcz (Poland), C Nachev (Bulgaria), Y Nikitin (Russian Federation), J Peleskã (Czech Republic), JA Staessen (Belgium)

Data management committee

T Kuznetsova, JA Staessen, JG Wang.

\section{Publication committee}

E Casiglia, K Kawecka-Jaszcz, Y Nikitin.

Advisory committee on molecular biology

G Bianchi (Milan), E Brand (Berlin), HA Struijker-Boudier (Maastricht).

\section{EPOGH-EurNetGen liaison}

A Dominiczak (Glasgow), JA Staessen (Leuven).

\section{EPOGH centres \\ Belgrum (Hechtel-Eksel)}

E Balkestein, R Bollen, H Celis, E Den Hond, L De Pauw, P Drent, D Emelianov, R Fagard, J Gąsowski, L Gijsbers, A Hermans, T Nawrot, L Thijs, Y Toremans, JA Staessen, S Van Hulle, JG Wang, R Wolfs. 
